\title{
Evaluation of New Technology Implementation via POC Analysis
}

\author{
Masaru Furukawa \\ Toyama University, Toyama City, Japan.
}

frukawa@eco.tovama-u.ac.jp

\begin{abstract}
In recent years the evolution of highly developed and complicated computerization has boosted the importance to business of IT infrastructure. Enhancement of business agility is not possible unless greater flexibility is built into IT infrastructure. More often than not, MIS's today are not flexible enough in this sense to agilely accommodate demands for system change incessantly confronting them.

We have been focusing our research on MIS flexibility, its evaluation and the development of methodology for its enhancement. This paper aims to present a comparative evaluation via POC (penalty of change) analysis of system alternatives involving a case of new technology implementation. To start with, we will define the concept of MIS flexibility. We will then describe an actual case of technology implementation and define the problem it involved and go on to illustrate the evaluation of MIS flexibility via $P O C$ analysis.
\end{abstract}

Keyword: Management information systems, MIS evaluation, MIS flexibility, IT infrastructure, penalty of change

\section{Introduction}

In recent years the evolution of highly developed and complicated computerization has boosted the importance to business of IT infrastructure. Enhancement of business agility is not possible unless greater flexibility is built into IT infrastructure. More often than not, MIS's today are not flexible enough in this sense to agilely accommodate demands for system change incessantly confronting them.

We have been focusing our research on MIS flexibility, its evaluation and the development of methodology for its enhancement. This paper aims to present a comparative evaluation via POC (penalty of change) analysis of system alternatives involving a case of new technology implementation. To start with, we will define the concept of MIS flexibility. We will then describe the actual technology implementation and define the problem it involved and go on to illustrate the evaluation of MIS flexibility via POC analysis, enumerating project risks accompanying the technology implementation.

\section{Definition of MIS Flexibility}

For the present purpose, let us draw on the definition of MIS flexibility and the scheme for its evaluation that we proposed in literature [1] and [2].

Material published as part of these proceedings, either on-line or in print, is copyrighted by Informing Science. Permission to make digital or paper copy of part or all of these works for personal or classroom use is granted without fee provided that the copies are not made or distributed for profit or commercial advantage AND that copies 1) bear this notice in full and 2) give the full citation on the first page. It is permissible to abstract these works so long as credit is given. To copy in all other cases or to republish or to post on a server or to redistribute to lists requires specific permission from the publisher at Publister@intormingscience.org

\section{(1) POC as a Substitute Index of MIS Flexibility}

Let us postulate MIS flexibility as an ability to absorb future change demands on an MIS, and let us express it formulaically with (1): 
Evaluation of New Technology Implementation

$$
\text { Flex }=\frac{\text { Const }}{g(C, T)}=\frac{1}{P O C}
$$

Penalty for A bsorbing Change Demand on MIS (POCMIS)

Penalty of MIS Implementation and its Risks (POCS)

Utility of Renovation of MIS Infrastructure $\left(U T L_{R}^{\prime}\right.$

where $C$ and $T$ stand for cost and time, respectively.

Formula (1) suggests that $P O C$ can serve as a substitute index for quantitative evaluation of the flexibility of an

MIS. It also obviously shows the following relationship between MIS flexibility and $P O C$ :

- If MIS flexibility is low, $P O C$ is high.

- If MIS flexibility is high, $P O C$ is low.

$P O C$ can serve as an index for measurement of the ability to absorb future demands for MIS change and can be accounted for in terms of cost and time.

\section{(2) Structure of MIS Flexibility}

As detailed in a relevant section in literature [2], a moderate renovation of MIS infrastructure can contribute to greater ease and efficiency of MIS modification [utility of renovation].

We know from experience that modification of an MIS is liable to expose it to system risks of some sorts or other, and that these risks are most to blame for impairment of MIS efficiency. However, if we moderately renovate IT infrastructure by building into it some preemptive risk-evasion strategies by anticipation, these strategies can be expected to reduce system risks that future MIS modification would almost inevitably entail. But implementation of such a renovation incurs a $P O C$ of its own [POC of renovation]. Therefore let us represent MIS flexibility in terms of the substitute index of $P O C$ as in Figure 1. This figure suggests that the $P O C\left[P O C_{R}\right]$ paid for a moderate renovation of MIS infrastructure can generate the benefit $\left[U T L_{R}\right]$ of reducing the $P O C\left(P O C_{S}\right)$ that processing of demands for system change would incur in future [utility of renovation] (Hereafter let us use the term "renovation of MIS infrastructure" to refer to the application of IT to an existing MIS for enhancement of its flexibility).

All this allows us to represent the $P O C$ of a whole MIS change $\left(P O C_{M I S}\right)$ with formula (2):

$$
P O C_{M I S}=P O C_{S}+\left(P O C_{R}-U T L_{R}\right)
$$

\section{A Case of Downsizing as an Implementation of New Technology}

\section{Attempts Made by Company $X$}

Printing paper container manufacturer $X$ had used on a mainframe a fairly sophisticated system for the scheduling and control of production targeted at printing and subsequent processes.

In 1994, with its stocks due to go public the next year (an organizational crisis), the manufacturer decided to build a sales management system. At that time downsizing was the fashion of the day in Japan. Jumping on the bandwagon, this company decided to remodel the management system on client/server architecture, which was an utterly new technology discontinuous with the technology hitherto used. The system development, accompanied by a purchase of PCs for development work was outsourced to a vendor. (Incidentally, on completion of the system development, the PCs were to be used in their routine work.) The development of the system on this basis took far less time than it would have on the mainframe. 
Adopting a prototyping-like development approach and using a relational DBMS (data base management system), they got a userfriendly application system completed one year later.

Unfortunately, however, they found that the capacity of the oneyear-old PCs was less than sufficient to let this system work. This obliged them to replace these PCs with the latest high-end ones at extra cost. They also had to upgrade to a new OS for the PCs, which for lack of upper compatibility burdened them with a great deal more extra cost. For several years after that, the company found to their great disappointment that with the PC-based system they had to cope with far more system failures and their recoveries than they would have with a mainframe-based system.

Several years later, they undertook another change, this time around in the system for data communication with customers. Adoption of this technology was the trend of the times. The change, however, took far more time and labor than they had expected due to deficiency in documentation. Besides, the heterogeneity of the technology that they had newly adopted continued to make fun of the engineers for quite a long

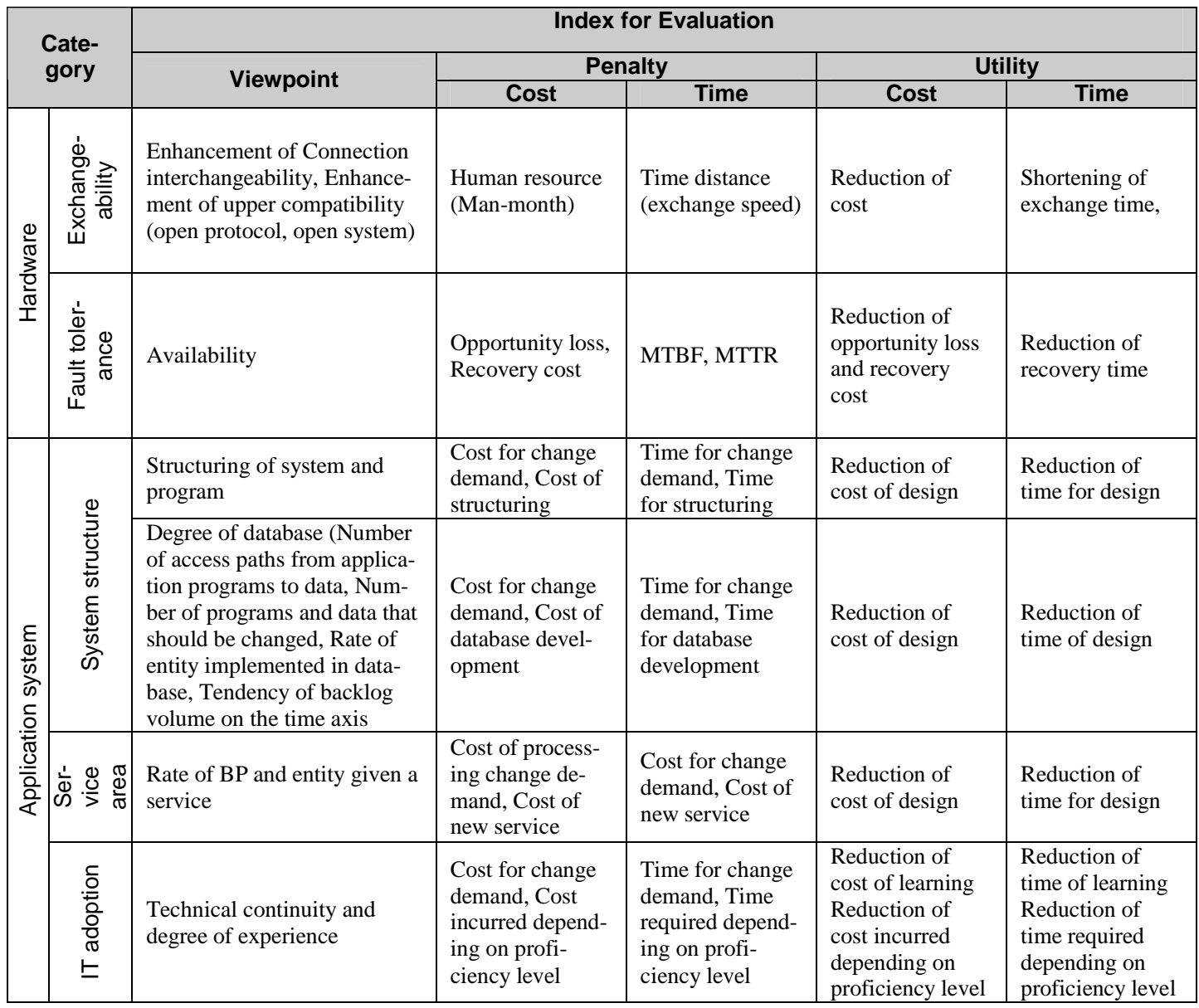

Table 1. Indexes for Evaluation of Internal Factors

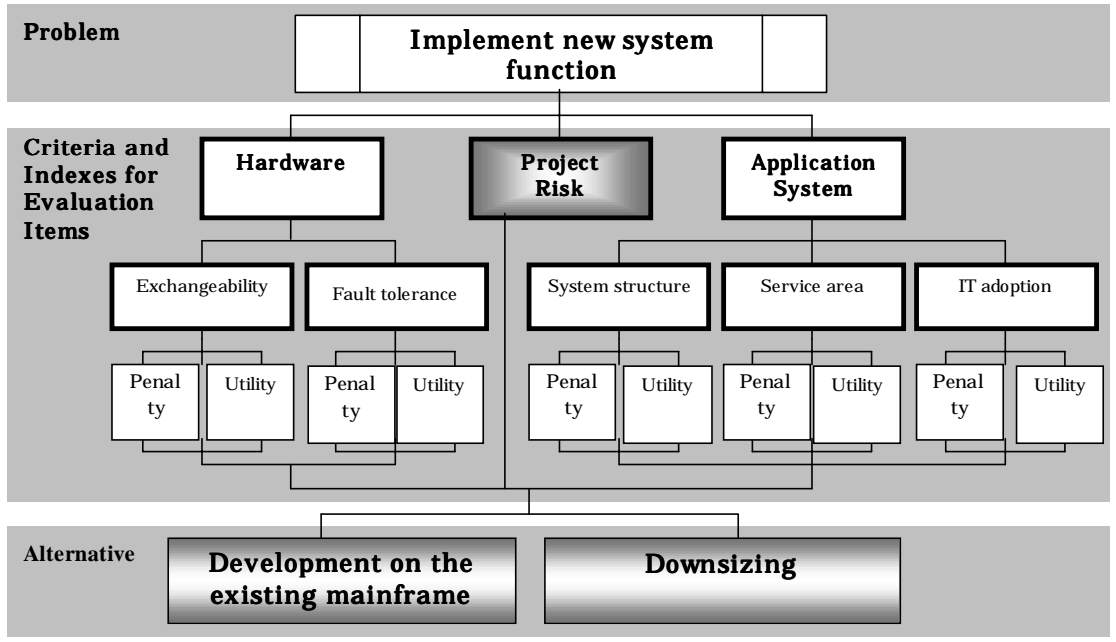

Figure 2. Definition of the Problem via AHP 
Evaluation of New Technology Implementation

time. Now, however, the heterogeneous monster, in a manner of speaking, has been tamed and become relatively obedient. In other words, new technology has come to acquire greater flexibility.

\section{Definition of the Problem via AHP}

Figure 2 shows the structure of the decision problem confronting the company, defined via AHP (analytic hierarchy process). The target of the problem is "to implement a new system function by the due date", and the alternatives to be evaluated are "development on the existing mainframe" on the one hand and "downsizing: i.e. development on client/server architecture" on the other. The difficulty with the problem,

\begin{tabular}{|c|c|c|c|c|}
\hline \multicolumn{4}{|c|}{ (1) Hardware } & Evaluation \\
\hline \multirow[b]{2}{*}{$P O C$} & Cost & \multicolumn{2}{|c|}{ Cost of hardware implementation for downsizing } & $30 \%$ \\
\hline & Time & \multicolumn{2}{|c|}{ Time for hardware implementation for downsizing } & $\begin{array}{l}150 \% \text { (because of the large number } \\
\text { of machines (or PCs)) }\end{array}$ \\
\hline \multicolumn{5}{|c|}{ Exchangeability } \\
\hline \multirow{2}{*}{\multicolumn{3}{|c|}{ Hardware exchange }} & \multicolumn{2}{|c|}{ Different protocols for one PC and another, and for PC and mainframe } \\
\hline & & & \multicolumn{2}{|c|}{ Good or poor affinity at the time of parts change } \\
\hline \multicolumn{3}{|c|}{ Basic software } & \multicolumn{2}{|c|}{ Not guaranteed high-order compatibility at the time of version-up } \\
\hline \multirow{4}{*}{ 咅 } & \multirow{2}{*}{ Index } & \multicolumn{2}{|c|}{ Manpower for exchange } & Faster \\
\hline & & \multicolumn{2}{|c|}{ Speed for exchange } & Faster \\
\hline & Cost & \multicolumn{2}{|c|}{ Cost of future exchange } & Will be low \\
\hline & Time & \multicolumn{2}{|c|}{ Time for future exchange } & Will be short \\
\hline
\end{tabular}

Fault tolerance

\begin{tabular}{|l|l|l|c|}
\hline \multicolumn{2}{|l|}{ Basic software } & System is unstable and operation rate low, compared with the use of mainframe \\
\hline \multicolumn{2}{|l|}{ Application system } & Insufficient tool for system management \\
\hline \multicolumn{3}{|l|}{ Operation } & More frequent system-down by operating-error, compared with the use of mainframe \\
\hline \multirow{4}{*}{ Index } & & Opportunity loss & Risk reduction by distributed system \\
\cline { 3 - 4 } & & Cost of recovery & Risk reduction by distributed system \\
\cline { 3 - 4 } & MTBF (mean time between failure) & Longer \\
\cline { 3 - 4 } & & MTTR (mean time to repair) & Shorter \\
\cline { 3 - 4 } & Cost & Cost of future exchange & Will be low \\
\cline { 3 - 4 } & Time & Time for future exchange & Will be short \\
\hline
\end{tabular}

(2) Application system

\begin{tabular}{|c|c|l|c|}
\multirow{2}{*}{ POC } & Cost & Cost of application system implementation for downsizing & $65 \%$ \\
\cline { 2 - 4 } & Time & Time for application system implementation for downsizing & $80 \%$ \\
\hline
\end{tabular}

\section{System structure}

\begin{tabular}{|c|c|c|c|c|}
\hline \multicolumn{3}{|c|}{ Ratio of structured program } & \multicolumn{2}{|l|}{ Structuralization only of access parts to DB } \\
\hline \multicolumn{3}{|c|}{ Ratio of structured system } & \multicolumn{2}{|l|}{ Complicated system interfaces } \\
\hline \multicolumn{3}{|c|}{ Ratio of DB } & Incompleteness of normalization & \\
\hline \multirow{6}{*}{ 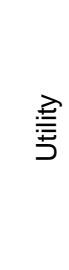 } & \multirow{4}{*}{ Index } & \multicolumn{2}{|c|}{ Number of access paths from application program to data } & $150 \%$ \\
\hline & & \multicolumn{2}{|c|}{ Number of programs that should be modified to cope with system demand } & $120 \%$ \\
\hline & & \multicolumn{2}{|c|}{$\begin{array}{l}\text { Number of data items that should be modified to cope with system de- } \\
\text { mand }\end{array}$} & $150 \%$ \\
\hline & & \multicolumn{2}{|c|}{ Ratio of entity implemented into database } & Higher by $30 \%$ \\
\hline & Cost & \multicolumn{2}{|c|}{ Cost of processing new demand for change } & Extra cost of outsourcing \\
\hline & Time & \multicolumn{2}{|c|}{ Time for processing new demand for change } & Longer than before \\
\hline
\end{tabular}

\section{Service area}

\begin{tabular}{|l|l|l|l|}
\hline \multicolumn{2}{|l|}{ Ratio of supported BP } & Addition of sales management system and its interface with production management system \\
\hline Ratio of supported Entity & Same as above & Cost reduction in sales management \\
\hline \multirow{2}{*}{ Utility } & Cost & Cost of new domain or new service area & Same as above \\
\cline { 2 - 5 } & Time & Time for offering new domain or new service area & \\
\hline
\end{tabular}

\section{IT adoption}

\begin{tabular}{|l|l|}
\hline Technological continuity & Extra dependence on skillful outside engineers for lack of technological continuity
\end{tabular}

\begin{tabular}{|c|c|l|c|}
\hline \multicolumn{2}{|c|}{ Degree of experience } & One year or more of learning & Decrease with increasing experience \\
\hline \multirow{2}{*}{ Utility } & Cost & Cost of offering service by means of new technology and technique & Same as above \\
\cline { 2 - 5 } & Time & Time for offering service by means of new technology and technique & .
\end{tabular}

Table 2. Evaluation of Downsizing (as compared with use of the mainframe) 
it should be noted, comes from "project risks" that use of unfamiliar technology for downsizing tends to entail. Hence the need for inclusion of the factor of "project risks" in the criteria for the analysis of the problem (See Figure 2). The analysis criteria for the problem also need to be broken down into different levels of abstraction ranging from the abstract to the detailed as shown in Table 1.

Table 2 shows the evaluation of downsizing as compared with development on the mainframe with regard to the indexes listed. The result of the evaluation indicates that development on the mainframe is prefer-

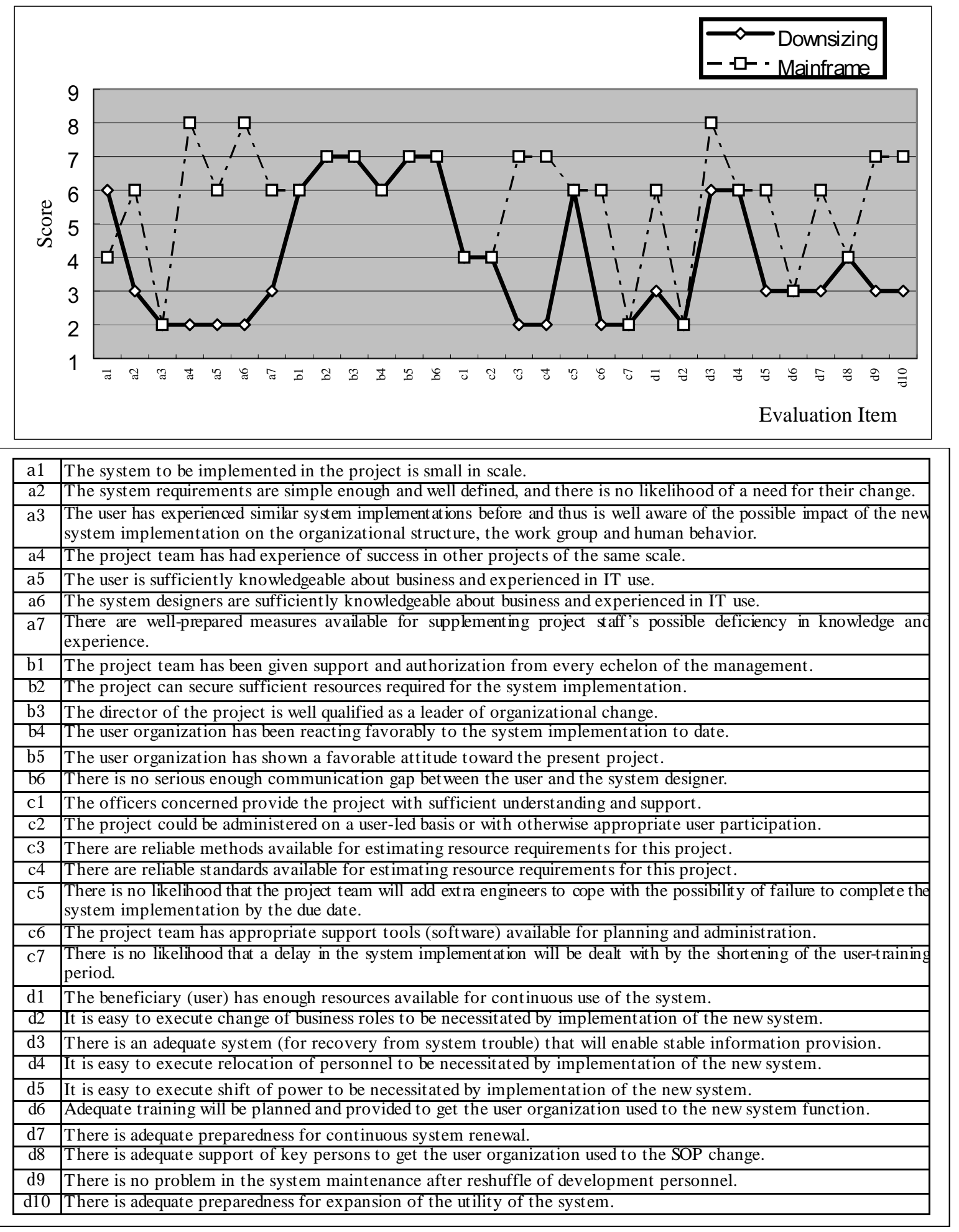

Figure 3. Evaluation of Project Risks 
Evaluation of New Technology Implementation

able to downsizing after all, since the former is found to be less vulnerable to project risks than the latter.

\section{Project Risks}

In solving this sort of problem, as noted above, project risks inevitably accompanying technology implementation are a crucial factor we must not fail to take into account. Target evaluation items listed in Figure 3 are excerpts from "System Success and Failure: Implementation" in literature [3], and a higher score in this figure means a smaller risk.

For company X, downsizing via implementation of client/server technology is an unexperienced and unfamiliar project. This is why the evaluation scores indicate that "downsizing" is riskier than the development of the system on the existing mainframe. The unfortunate choice made by this company is not so surprising. We often hear of cases of MIS implementation that have met with troubles such as failure to deliver by the due date, excess over the estimates, productivity deterioration (increase of backlogs), malfunctioning (activity inability, operational inability, increase of bugs), system failure (failure of a system to be used as intended).

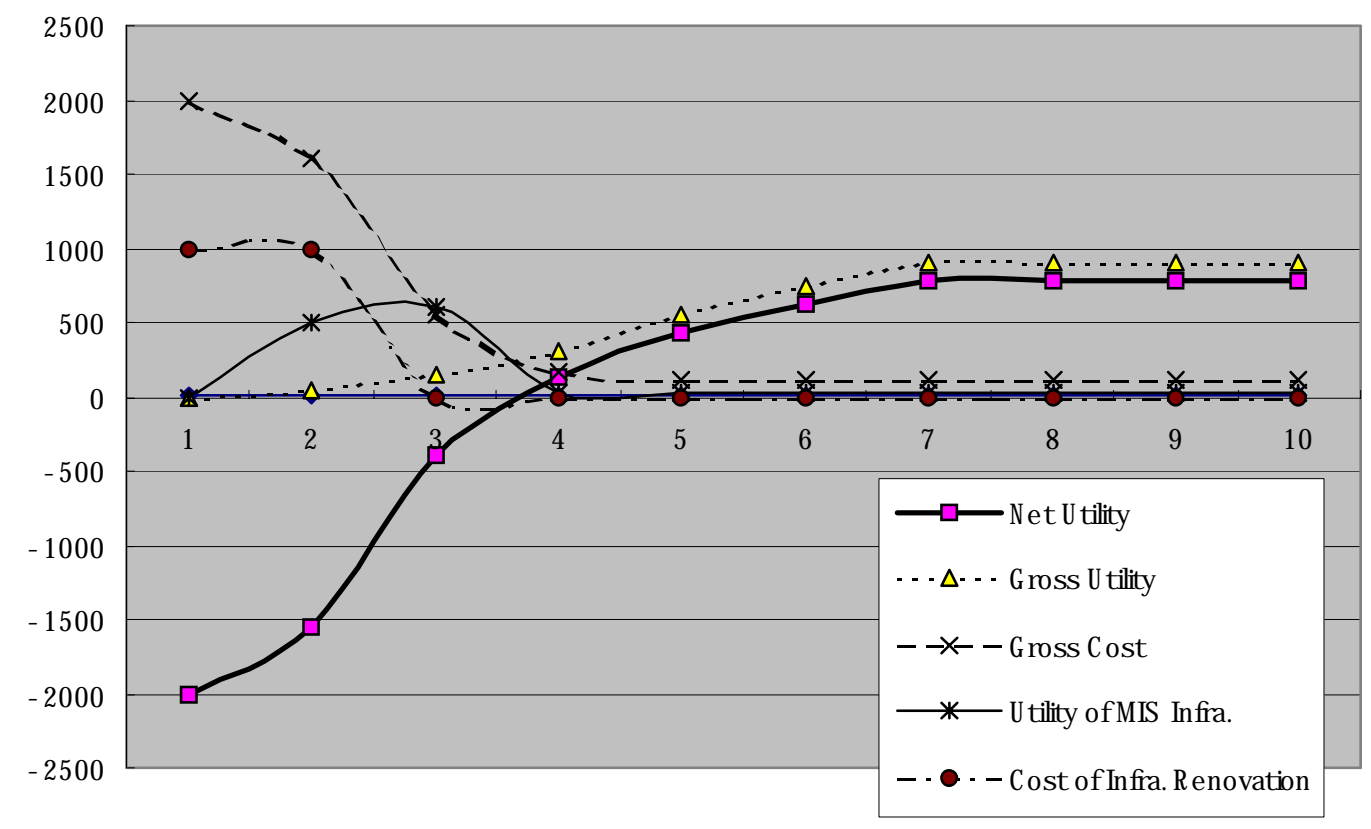

\begin{tabular}{|c|c|c|c|c|c|c|c|c|c|c|c|}
\hline \multirow{2}{*}{$\begin{array}{c}\text { Fiscal } \\
\text { Year }\end{array}$} & \multirow{2}{*}{$\begin{array}{c}\text { Net } \\
\text { Utility }\end{array}$} & \multirow{2}{*}{$\begin{array}{l}\text { Gross } \\
\text { Utility }\end{array}$} & \multicolumn{3}{|c|}{ Utility } & \multirow{2}{*}{$\begin{array}{c}\text { Gross } \\
\text { Cost }\end{array}$} & \multicolumn{3}{|c|}{ Cost } & \multirow{2}{*}{$\begin{array}{c}\text { Utility of } \\
\text { MIS } \\
\text { Infra. }\end{array}$} & \multirow{2}{*}{$\begin{array}{c}\text { Cost of } \\
\text { Infra. } \\
\text { Renovation }\end{array}$} \\
\hline & & & MIS1 & MIS2 & MIS3 & & MIS1 & MIS2 & MIS3 & & \\
\hline 1 & -2000 & 0 & 0 & 0 & 0 & 2000 & 1000 & 0 & 0 & 0 & 1000 \\
\hline 2 & -1550 & 50 & 50 & 0 & 0 & 1600 & 100 & 1000 & 0 & 500 & 1000 \\
\hline 3 & -400 & 150 & 100 & 50 & 0 & 550 & 50 & 100 & 1000 & 600 & 0 \\
\hline 4 & 130 & 300 & 150 & 100 & 50 & 170 & 50 & 50 & 100 & 30 & 0 \\
\hline 5 & 430 & 550 & 300 & 150 & 100 & 120 & 50 & 50 & 50 & 30 & 0 \\
\hline 6 & 630 & 750 & 300 & 300 & 150 & 120 & 50 & 50 & 50 & 30 & 0 \\
\hline 7 & 780 & 900 & 300 & 300 & 300 & 120 & 50 & 50 & 50 & 30 & 0 \\
\hline 8 & 780 & 900 & 300 & 300 & 300 & 120 & 50 & 50 & 50 & 30 & 0 \\
\hline 9 & 780 & 900 & 300 & 300 & 300 & 120 & 50 & 50 & 50 & 30 & 0 \\
\hline 10 & 780 & 900 & 300 & 300 & 300 & 120 & 50 & 50 & 50 & 30 & 0 \\
\hline Total & 360 & 5400 & 2100 & 1800 & 1500 & 5040 & 1500 & 1450 & 1400 & 1310 & 2000 \\
\hline
\end{tabular}

Figure 4. Net Utility of MIS on the Time Axis 


\section{Consideration}

Generally implementation of new technology will expose a system to the high risk of system failures (i.e. an information system that either won't perform as expected, fails to be operational at a specified time, or cannot be used in the way it is intended to be). Moreover, successful implementation does not mean an immediate realization of effectiveness since it takes considerable time for the users to acquire expertise and proficiency in the use of the new system. System trouble obstructs flexible use of an MIS. A project like the present one whose due date is critical requires a high degree of MIS flexibility.

In this case, to obtain the same MIS function, it would have been more advantageous if they had modified the existing MIS working on the mainframe since it would have incurred a far smaller POC than did the implementation of new technology.

Now, however, we know that new technology has come to be flexibly and effectively used thanks to the accumulation of engineers' bitter experiences, their efforts to tame intractable technology and technological progress in general in recent years. As Figure 4 graphically shows, all this is good enough proof that in general MIS evaluation needs to be executed longitudinally on the time axis.

\section{Future-oriented POC Analysis}

In this section, let us attempt to expand and generalize the $P O C$ analysis we proposed in literature [1].

Enhancement of MIS flexibility cannot be realized unless the possibility of system risks is reduced by means of moderate strategic renovation of MIS infrastructure. This infrastructure renovation actually means applying preemptive risk-evasion strategies in anticipation of future MIS modification. What we should consider in this connection is how to evaluate what combination of system alternatives would incur the least $P O C$ (cost and time). For this purpose, it is necessary to enumerate a possible set of riskevasion strategies we should provide for application to the combination of system alternatives, and evaluate both the penalty of change the very provision of these strategies would incur and the utility that their application would also generate (i.e. their utility in reducing penalty that we would otherwise have to pay when addressing change demands in future).

Since anticipatory provision of evasion strategies for possible future system changes, by its very nature, involves predictive uncertainty, it should be dealt with as a probabilistic event. Therefore, before going on into our detailed discussion, let us refer to a related idea involving a probabilistic event in the form of formula (3), an idea proposed by Chryssolouris, G. et al [4] in the context of the evaluation of flexible manufacturing system:

$$
P O C=\sum_{s=1}^{n} \operatorname{Pe}\left(X_{s}\right) \operatorname{Pr}\left(X_{s}\right)
$$

where

$$
\begin{aligned}
& X_{s}=\text { the state after change } s(1,2, \ldots, S) \\
& \operatorname{Pe}\left(X_{s}\right)=\text { the penalty for change } s, \\
& \operatorname{Pr}\left(X_{s}\right)=\text { the occurrence probability of change } s .
\end{aligned}
$$

\begin{tabular}{|c|c|c|c|c|c|c|}
\hline \multicolumn{4}{|c|}{ Change Demand $k(l=3)$} & \multirow{2}{*}{\multicolumn{2}{|c|}{$\begin{array}{c}\text { Set of } \\
\text { Risk } \\
\text { Evasion } \\
\text { Strate- } \\
\text { gies }\end{array}$}} & \multirow{2}{*}{$\begin{array}{l}\text { Occur- } \\
\text { rence } \\
\text { Probabil- } \\
\text { ity of } \\
\text { Change } X\end{array}$} \\
\hline \multirow{2}{*}{$\begin{array}{l}\text { or } \\
\text { II } \\
2 \\
2\end{array}$} & \multicolumn{3}{|c|}{$\begin{array}{l}\text { Combination of } \\
\text { Alternatives }\left(A l_{j p}\right)\end{array}$} & & & \\
\hline & $\begin{array}{l}k=1, \\
j=2\end{array}$ & $\begin{array}{r}k=2, \\
j=2\end{array}$ & $\begin{array}{l}k=3, \\
j=2\end{array}$ & \multicolumn{2}{|c|}{$\begin{array}{c}S t_{i p} \\
i=n(p)\end{array}$} & $\operatorname{Pr}\left(X_{i p}\right)$ \\
\hline \multirow{5}{*}{. } & \multirow{5}{*}{$A l_{l l}$} & \multirow{5}{*}{$A l_{12}$} & \multirow{5}{*}{$A l_{13}$} & \multirow{5}{*}{$\mid \begin{array}{l}\text { II } \\
\text { II }\end{array}$} & $S t_{I_{I}}$ & $\mathrm{Pr}_{11}$ \\
\hline & & & & & $S t_{21}$ & $\mathrm{Pr}_{21}$ \\
\hline & & & & & $S_{t_{31}}$ & $\mathrm{Pr}_{31}$ \\
\hline & & & & & $S t_{41}$ & $\mathrm{r}_{4}$ \\
\hline & & & & & $S t_{51}$ & \\
\hline \multirow{2}{*}{2} & \multirow{2}{*}{$A l_{l l}$} & \multirow{2}{*}{$A l_{12}$} & \multirow{2}{*}{$A l_{23}$} & \multirow{2}{*}{$\pi$} & $S t_{12}$ & $\mathrm{Pr}_{12}$ \\
\hline & & & & & $S_{t 22}$ & $\mathrm{r}_{22}$ \\
\hline \multirow{2}{*}{3} & \multirow{2}{*}{$A l_{l l}$} & \multirow{2}{*}{$A l_{22}$} & \multirow{2}{*}{$A l_{13}$} & \multirow{2}{*}{$\pi$} & $S t_{13}$ & $\mathrm{Pr}_{13}$ \\
\hline & & & & & $S t_{23}$ & $\mathrm{Pr}_{23}$ \\
\hline \multirow{3}{*}{4} & \multirow{3}{*}{$A l_{l l}$} & \multirow{3}{*}{$A l_{22}$} & \multirow{3}{*}{$A l_{23}$} & \multirow{3}{*}{ in } & $S t_{14}$ & $\operatorname{Pr}_{14}$ \\
\hline & & & & & $\mathrm{St}_{24}$ & $\mathrm{Pr}_{4}$ \\
\hline & & & & & $S_{34}$ & $\mathrm{Pr}_{3}$ \\
\hline \multirow[t]{2}{*}{5} & \multirow{2}{*}{$A l_{2 l}$} & \multirow{2}{*}{$A l_{12}$} & \multirow{2}{*}{$A l_{13}$} & \multirow{2}{*}{$\pi$} & $S t_{15}$ & $\overline{P_{r_{1}}}$ \\
\hline & & & & & $S t_{25}$ & 25 \\
\hline \multirow{2}{*}{6} & \multirow{2}{*}{$A l_{21}$} & $A l_{12}$ & $A l_{23}$ & $\pi$ & $S t_{16}$ & $\mathrm{Pr}_{16}$ \\
\hline & & & & & $S t_{22}$ & $\mathrm{Pr}_{26}$ \\
\hline & & & & & $S t_{17}$ & $\mathrm{Pr}_{17}$ \\
\hline 7 & $A l_{21}$ & $A l_{22}$ & $A l_{13}$ & ii & $S t_{27}$ & 1127 \\
\hline & & & & & $S t_{37}$ & $\mathrm{Pr}_{37}$ \\
\hline & & & & & $S t_{18}$ & \\
\hline 8 & $A l_{21}$ & $A l_{22}$ & $A l_{23}$ & $\pi$ & $S t_{28}$ & $\mathrm{Pr}_{28}$ \\
\hline & & & & & $S_{t 38}$ & $\mathrm{Pr}_{38}$ \\
\hline
\end{tabular}

The calculation of $P O C$ can be viewed as an application of single-attribute decision-making under conditions of uncer-

Table 3. Factors for $P O C$ Calculation 
tainty (i.e., the decision problem of selecting a combination of system alternatives for the enhancement of MIS flexibility); $X_{s}$ is a possible future scenario (i.e., the state brought about by the implementation of the sth system change); $\mathrm{Pe}\left(X_{s}\right)$ is the attribute value for the future scenario (i.e., required management resources for the sth change); and $\operatorname{Pr}\left(X_{s}\right)$ is the probability of the possible occurrence of the future scenario; the numerical value of $P O C$ is the expected value of the penalty payable for the system change leading to the possible future scenario.

Here, let us represent a change demand as $k(1 \leq k \leq l)$, a system alternative for a change demand $k$ as $j(1 \leq j \leq m(k))$ and a combination of system alternatives for a change demand as $p(1 \leq p \leq q)$. Where the number of change demands is $l$, the number (represented as $q$ ) of combinations of system alternatives for processing all change demands can be represented as $q=n(1) \times n(2) \times \ldots \times n(l)(q=8$ in Table 3.). On the other hand, let us represent a set of risk-evasion strategies for $p$ as $i(1 \leq i \leq n(p))$ and enumerate a set of risk-evasion strategies $(i)$ to be applied to each $p$ of $q$ combinations of system alternatives and let us give the notation of $\operatorname{Pr}\left(X_{i p}\right)$ to the probability of the occurrence of the state of affairs where a set of risk-evasion strategies $(i)$ will be applied. Then, the expected value of $P O C_{p}$ ( $P O C$ payable for execution of each $p$ of the $q$ combinations of system alternatives) can be represented with formula (4) after the fashion of Chryssolouris, G. et al [4].

$$
P O C_{p}=\sum_{i=1}^{n(p)} \operatorname{Pe}\left(X_{i p}\right) \operatorname{Pr}\left(X_{i p}\right)
$$

In order to process all $(=l)$ change demands, we must execute $q$ combinations of system alternatives for them. And each of these combinations of system alternatives is supposed to have been provided with a set of risk-evasion strategies in advance. An aim of this paper is to establish the methodology for selecting a system plan comprised of combinations of system alternatives and sets of risk-evasion strategies, which will best serve the purpose of MIS flexibility enhancement. A combination of system alternatives that will show the lowest value of $P O C\left(P O C_{\min }\right)$ can be represented with formula (5).

$$
P O C_{\min }=\sum_{p=1}^{q} \min P_{p}
$$

As the structure of MIS flexibility in Figure 1 visually shows, enhancement of MIS flexibility can only be realized by reduction of system risks via renovation of IT infrastructure. In order to evaluate a system plan, therefore, we must enumerate all sets of risk-evasion strategies to be applied to combinations of system alternatives, and then we must estimate both the penalty for the provision of the strategies and the application of the alternatives $\left(P O C_{R}, P O C_{S},\right)$ and the utility $\left(U T L_{R}\right)$ that the application of the strategies will generate in the enhancement of MIS flexibility.

The following formula (6) represents the effect of the application of a set of risk-evasion strategies to a combination of system change alternatives in future. This formula means that a combination of system alternatives that will incur the lowest penalty $\left(P O C_{\min }\right)$ can be identified through close scrutiny of what set of risk-evasion strategies will be the best one to be applied to a combination of system alternatives for processing all change demands. There can be no doubt about the validity of this idea, since it closely reflects the fact that one and the same IT infrastructure is shared by all possible application systems.

$$
P e\left(X_{i p}\right)=P O C_{S}(p)+P O C_{R}(i p)-U T L_{R}(i p)
$$

where

$\operatorname{POC}_{S}(p)=$ the penalty for applying a combination of system alternatives $p$ to all change demands (without applying a set of risk-evasion strategies), 
$P O C_{R}(i p)=$ the penalty for providing a set of risk-evasion strategies $i$ for a combination of system alternatives $p$,

$U T L_{R}(i p)=$ the utility of applying a set of risk-evasion strategies $i$ to a combination of system alternatives $p$.

\section{Conclusion and Challenges for Us}

In this paper we have considered MIS flexibility with respect to a case of downsizing. What we have learned from this consideration is that project risks are a crucial factor that should be included in the evaluation of MIS flexibility and that evaluation must be executed longitudinally on the time axis.

The challenges still facing us are the integration of project risk analysis and $P O C$ calculation. For this purpose, we must find a workable method of estimating future system risks and utility accruing from new technology implementation.

\section{References}

[1] Furukawa, M. (2001a). Conceptual Model for MIS Flexibility Evaluation, Managing Information Technology in a Global Economy. Ed. Khosrowpour, Information Resource Management Association. pp.831-839.

[2] Furukawa, M. (2001b), Database Agile Management Dependent on MIS Infrastructure, The Proceedings of the 2001st International Conference of Informing Science, Cracow, Poland, pp.198-213.

[3] Laudon, K. and Laudon, J. (2000). "System Success and Failure: Implementation", Management Information Systems: Organization and technology in the Networked Enterprise, Prentice-Hall Inc., pp.398-431.

[4] Chryssolouris, G. (1996). Flexibility and Its Measurement, Annals of the CIRP, Vol.45/2/1996, pp.581-587.

\section{Biography}

Masaru Furukawa is a faculty member of TOYAMA University in Japan, where he teaches management information systems. He has ten years of practical experience as a manager of MIS division in a large enterprise and eight years of teaching experience as a Professor.

For edition of the manuscript for its English, thanks are owed to Akira Minami, an ex-professor of English at Toyama Prefectural University, Japan. 